\title{
Genetic parameters for handling and milking temperament in Danish first-parity Holstein cows
}

\author{
R. S. Stephansen, ${ }^{*}{ }^{1}$ A. Fogh, ${ }^{*}$ and E. Norbergt‡ \\ *Nordic Cattle Genetic Evaluation, Skejby, DK-8200 Aarhus, Denmark \\ †Department of Molecular Biology and Genetics, Aarhus University, 8830 Tjele, Denmark \\ ‡Department of Animal and Aquacultural Sciences, Norwegian University of Life Sciences, 1433 Ås, Norway
}

\section{ABSTRACT}

The human-animal relationship in dairy cattle is reflected in the trait "temperament" in breeding programs and is mainly based on observations by farmers. However, farmers' knowledge of an individual cow's temperament decreases with an increased herd size, and this has been the case in many countries during the last decades. The aim of this study was to investigate if temperament recorded by classifiers and automatic milking systems is heritable, and estimate the genetic relationship with farmer-assessed temperament. Farmer-assessed temperament is defined as the overall assessment of the individual cows' temperament at milking and handling. Data on handling temperament were recorded by Danish classifiers from October 2016 to April 2017 on a 1 to 9 scale specially designed for this purpose. Data from automatic milking systems were recorded from January 2010 until April 2017, where connection time and number of attachments per teat were classified as milking temperament traits. Estimated heritabilities were relatively low for handling temperament (0.13) and farmer-assessed temperament (0.10). For milking temperament traits, connection time showed higher heritability than number of attachments per teat ( 0.36 and 0.26 , respectively). The genetic correlation between farmer-assessed temperament and handling temperament was highly favorable (0.84). The genetic correlations between handling temperament and the 2 milking temperament traits, connection time and number of attachments per teat, were low $(-0.02$ and -0.10 , respectively). Moderate genetic correlations were estimated between farmer-assessed temperament and connection time $(-0.29)$ and between farmerassessed temperament and number of attachments per teat $(-0.37)$. The genetic correlations and heritabilities suggest a basis for further investigations of the possibil-

Received March 23, 2018.

Accepted July 17, 2018.

${ }^{1}$ Corresponding author: rass@SEGES.dk ity of including handling or milking temperament traits (or both) in the breeding program for temperament in dairy cattle.

Key words: dairy cattle, handling temperament, milking temperament, genetic parameter

\section{INTRODUCTION}

Most Danish dairy cows are kept in loose cubicle barns where contact with humans mostly occurs at the time of milking, unless they are milked in automatic milking systems (AMS). Automatic milking systems has become popular in Denmark the 2 past decades and is installed for $\sim 25 \%$ of Danish herds (Lauritsen, 2014). Other situations with human-animal interaction are at the time around and during calving, insemination, pregnancy test, veterinary treatments, and so on. To avoid injuries of both humans and animals, as well as minimizing the labor time, it is important that the cow keeps calm and does not show aggressive behavior in these situations. Furthermore, it has been shown that fearful cows tend to have elevated SCC (Ivemeyer et al., 2011).

The human-animal relationship is reflected in the trait "temperament" in Nordic breeding programs for dairy cattle, with an economic benefit of calmer animals (Pedersen et al., 2008). Burrow (1997) has defined temperament as "the animal's behavioral response to handling by humans." Temperament is evaluated for both dairy and beef cattle using different recording scales with different purposes and resulting in heritabilities $\left(\mathrm{h}^{2}\right)$ between 0.04 (Kramer et al., 2013) and 0.49 (Nkrumah et al., 2007). In several studies, $\mathrm{h}^{2}$ for handling temperament in beef cattle have been estimated (Le Neindre et al., 1995; Nkrumah et al., 2007; Hoppe et al., 2010), but no studies on handling tests performed on dairy cows have been found. However, Murphey et al. (1980) found that dairy cattle on pasture are generally more approachable by humans than beef cattle. This may indicate that dairy cattle in the past have been selected for docility to a larger extent than beef 
cattle. On the other hand, there are several studies on milking and general temperament in dairy cattle, and $\mathrm{h}^{2}$ have been estimated to be in the range between 0.04 and 0.38 (Rensing and Ruten, 2005; Sewalem et al., 2011; Kramer et al., 2013).

In the Nordic Cattle Genetic Evaluation, $\mathrm{a} \mathrm{h}^{2}$ of 0.13 is used when estimating breeding values for the temperament trait in Danish Holstein (SEGES Cattle, 2015-2016). However, this trait is assessed by farmers and is a subjective assessment of the individual cow's behavior at milking and handling. With an rapidly increasing herd size in Denmark (Hansen, 2015), the accuracy of the temperament registrations might decrease because farmers spend less time on each cow, leading to less knowledge about the behavior of the individual cow. To ensure that future registrations on temperament are valuable in a breeding program, we need to include more objective measurements.

The aim of this study is to estimate $\mathrm{h}^{2}$ for handling and milking temperament by utilizing data from classifiers and AMS, and estimate the genetic relationship between these traits and the farmer-assessed temperament (FAT) evaluation.

\section{MATERIALS AND METHODS}

\section{Traits and Trait Definition}

Danish dairy farmers score the first parity cows for temperament once in the first lactation. The trait is a combination of total behavior of the individual cow at handling and milking. The farmer uses a 1 to 9 scale, where a score of 9 means extremely calm behavior, a score of 5 means average herd behavior, and a score of 1 means extremely difficult behavior. The classifiers use a modified scale to assess handling temperament (HT). This scale (1-9) is similar to the one used by the farmers, but with more detailed descriptions of the individual categories.

To score HT, it is preferred that the cow is restrained in headlock barriers. However, not all Danish farmers have headlock barriers for classification. In that case, the classifier or farmer must move the cow into a cubicle and classify HT right after conformation classification (nonrestrained). This approach was chosen to include data from herds without headlock barriers to maximize the number of registrations.

Data from Lely AMS were used to evaluate milking temperament. Milking temperament was divided into 2 traits: connection time (CT) and number of attachments per teat (nApT). Both traits were measured by the AMS, and CT is defined as the time spend on attaching the teat cups, where $\mathrm{nApT}$ is defined as the average number of attachment attempts per teat per milking. If nApT exceeded 10, then the traits was set to 10 , and if there was a failure to attach then nApT was set to 11 . Because $n A p T$ is a counting variable, it was transformed using the natural logarithm (log_nApT). Both traits were defined as the mean of all the daily records during the period 3 to 100 DIM, based on minimum 20 records. The first 2 DIM were excluded to avoid unreliable data that may occur when cows start getting milked in AMS. Only data from successful milkings were used to calculate rear teat placement, udder balance, udder depth, and CT. Records from AMS, where total time in the milking robot exceeds $30 \mathrm{~min}$, or starting time in the milking robot was after end time, were removed. Average lactation stage was calculated as the mean DIM of all records 3 to 100 DIM for cows milked in AMS to account for cows that not have fulfilled the trial period (3-100 DIM). This trait consisted of 10 classes with 10-d interval.

\section{Animals and Data}

Data on 158,000 first parity Danish Holstein cows (including Danish Red Holstein) from 2,641 herds were collected for milking temperament and FAT from January 2010 until March 2017. Handling temperament was registered by classifiers from October 2016 until April 2017 , and the distribution of records among traits is presented in Table 1. The pedigree was traced back 3 generations in the Danish cattle database. The cows included in this study were primarily housed in loose cubicle housing stables. For different reasons, not all cows were scored for FAT by the farmer (they missed the evaluation of the cow or they generally do not submit temperament classification). The cows were evaluated for HT by Danish classifiers simultaneously with the routine classification of conformation. Data from AMS were used for evaluation of milking temperament and the daily AMS records were collected simultaneously with milk yield recording once every month. Udder coordinates detected in the AMS were used to generate 7 classes for rear teat placement, udder depth, and udder balance, respectively. Furthermore, the average number of attached quarters per milking was calculated. The trait was multiplied with 10 , generating 28 classes. These 4 AMS traits where used, in the model, to account for their relationship to CT and nApT. All traits used for genetic evaluation were single records per cow.

\section{Statistical Analysis}

Data editing were performed with SAS 9.3 (SAS Institute Inc., Cary, NC). The model used for FAT in this 
Table 1. Number of cows for each trait (on diagonal) and cows with observations on multiple traits (above diagonal) for current handling and milking temperament

\begin{tabular}{lccc}
\hline Trait $^{1}$ & FAT & HT & AMS temperament \\
\hline FAT & 126,614 & 1,448 & 3,857 \\
HT & & 8,108 & 816 \\
AMS temperament & & & 27,726 \\
\hline
\end{tabular}

${ }^{1} \mathrm{FAT}=$ farmer-assessed temperament; $\mathrm{HT}=$ handling temperament, assessed by classifiers; AMS = automatic milking system.

study is similar to the model used for breeding value estimation. (this model is described in more detail in the annual breeding report: SEGES Cattle, 2015-2016). Variance components for the 4 traits were estimated using a univariate animal model.

For HT the following model was used:

$$
\mathrm{Y}_{\mathrm{ijkno}}=\mathrm{CA}_{\mathrm{i}}+\mathrm{MAC}_{\mathrm{j}}+\mathrm{INSP}_{\mathrm{k}}+\text { hys }_{\mathrm{n}}+\mathrm{a}_{\mathrm{o}}+\mathrm{e}_{\mathrm{ijkno}} .
$$

For FAT the following model was used:

$$
\mathrm{Y}_{\mathrm{ijno}}=\mathrm{CA}_{\mathrm{i}}+\mathrm{MAC}_{\mathrm{j}}+\text { hys }_{\mathrm{n}}+\mathrm{a}_{\mathrm{o}}+\mathrm{e}_{\mathrm{ijno}} \text {. }
$$

For CT and log_nApT the following model was used:

$$
\mathrm{Y}_{\mathrm{ilmno}}=\mathrm{CA}_{\mathrm{i}}+\mathrm{LS}_{\mathrm{l}}+\mathrm{AMS}_{\mathrm{CORm}}+\mathrm{hys}_{\mathrm{n}}+\mathrm{a}_{\mathrm{o}}+\mathrm{e}_{\mathrm{ilmno}} \text {, }
$$

where $\mathrm{Y}=\mathrm{HT}$, FAT, CT, or log_nApT; $\mathrm{CA}_{\mathrm{i}}=$ fixed effects of calving age $\mathrm{i}(\mathrm{i}=20,21, \ldots, 34) ; \mathrm{MAC}_{\mathrm{j}}=$ fixed effects of month after calving $\mathrm{j}(\mathrm{j}=1,2, \ldots, 10)$; $\mathrm{INSP}_{\mathrm{k}}=$ fixed effects of (classifier $\times$ year $\times$ month $) \mathrm{k}$ $(\mathrm{k}=1,2, \ldots, 38) ; \mathrm{LS}_{1}=$ fixed effect of lactation stage $\mathrm{l}(\mathrm{l}=1,2, \ldots 10) ; \mathrm{AMS}_{\mathrm{CORm}}=$ fixed effect of $\mathrm{AMS}$ coordinates (teat placement back, udder depth, udder balance, and teats attached $) \mathrm{m}(\mathrm{m}=1,2, \ldots, 28)$; hys $=$ random effect of herd $\times$ year $\times$ season; $\mathrm{a}_{\mathrm{o}}=$ random additive genetic effect of cow; and $\mathrm{e}=$ random residual.

A multitrait model was used to estimate genetic correlations between HT, FAT, CT, and log_nApT:

$$
\left[\begin{array}{l}
\mathbf{y}_{1} \\
\mathbf{y}_{2} \\
\mathbf{y}_{3} \\
\mathbf{y}_{4}
\end{array}\right]=\left[\begin{array}{cccc}
\mathbf{X}_{1} & 0 & 0 & 0 \\
0 & \mathbf{X}_{2} & 0 & 0 \\
0 & 0 & \mathbf{X}_{3} & 0 \\
0 & 0 & 0 & \mathbf{X}_{4}
\end{array}\right]\left[\begin{array}{c}
\mathbf{b}_{1} \\
\mathbf{b}_{2} \\
\mathbf{b}_{3} \\
\mathbf{b}_{4}
\end{array}\right]\left[\begin{array}{cccc}
\mathbf{Z}_{1} & 0 & 0 & 0 \\
0 & \mathbf{Z}_{2} & 0 & 0 \\
0 & 0 & \mathbf{Z}_{3} & 0 \\
0 & 0 & 0 & \mathbf{Z}_{4}
\end{array}\right]\left[\begin{array}{c}
\mathbf{a}_{1} \\
\mathbf{a}_{2} \\
\mathbf{a}_{3} \\
\mathbf{a}_{4}
\end{array}\right]+\left[\begin{array}{c}
\mathbf{e}_{1} \\
\mathbf{e}_{2} \\
\mathbf{e}_{3} \\
\mathbf{e}_{4}
\end{array}\right],
$$

where $\mathbf{y}_{i}$ is the vector of $i$ th trait, $\mathbf{b}_{i}$ is the vector of fixed effects for the $i$ th trait, $\mathbf{a}_{i}$ is the vector of random animal effects for the $i$ th trait, $\mathbf{e}_{i}$ is the vector of random residual effects for the $i$ th trait, and $\mathbf{X}_{i}$ and $\mathbf{Z}_{i}$ are incidence matrices relating records to the $i$ th trait to fixed and random effects, respectively (Mrode and Thompson, 2014).
Estimation of variance and covariance components were performed in DMU using the AI-REML procedure (Madsen and Jensen, 2013). The convergence criterion used was a change in the norm of the update. The heritability for traits with 2 random effects were defined as intra-herd heritability: $h^{2}=\frac{\sigma_{A}^{2}}{\sigma_{P}^{2}}$ (Heringstad et al., 2006). The method for estimation of standard error (SE) of the $\mathrm{h}^{2}$ for the models with more than one random effect (FAT and HT) is described by Jensen and Madsen (2002). The correlations were defined as significantly different from zero if the correlation $\pm \mathrm{SE} \times$ $1.96 \neq 0$. The genetic correlation between FAT recorded in AMS- and conventional milking herds were estimated using a bivariate model. Only in this model the environmental covariance was assumed to be 0 (Mrode and Thompson, 2014).

\section{RESULTS AND DISCUSSION}

Results from the analysis of the 4 traits using univariate models are presented in Table 2 . The additive and phenotypic variances were larger for HT compared with FAT. The $\mathrm{h}^{2}$ are slightly higher for HT than for FAT, but the SE is also larger. The $\mathrm{h}^{2}$ for the AMS traits shows a moderately high $\mathrm{h}^{2}$ for $\mathrm{CT}(0.36)$, whereas it is moderate for log_nApT (0.26).

The estimated $\mathrm{h}^{2}$ and the genetic correlations between the 4 traits are presented in Table 3. By using this multitrait model, the $\mathrm{h}^{2}$ for HT was increased compared with the estimate from the univariate model. The genetic correlation between HT and FAT was high (0.84 $\pm 0.06)$ and favorable. The genetic correlations between $\mathrm{HT}$ and the 2 AMS traits were low and associated with a large SE. Both correlations were negative and not significantly different from zero $(P>0.05)$. The genetic correlation between FAT and log_nApT are negative, favorable, and significant $(-0.37 \pm 0.07)$. The $\mathrm{h}^{2}$ was larger for CT $(0.36 \pm 0.02)$ compared with log_nApT $(0.26 \pm 0.02)$. Furthermore, the 2 AMS traits CT and log_nApT were highly genetically correlated $(0.91 \pm$ $0.01)$.

Additionally, it was assessed if FAT evaluated by farmers in AMS systems was the same trait as FAT 
Table 2. Mean, heritability $\left(h^{2}\right)$, and additive $\left(\sigma_{A}^{2}\right)$ and phenotypic variance $\left(\sigma_{P}^{2}\right)$ for different temperament traits estimated with univariate models

\begin{tabular}{lccccc}
\hline Trait $^{1}$ & Mean \pm SD & $\sigma_{A}^{2}$ & $\sigma_{H Y S}^{2}{ }^{2}$ & $\sigma_{P}^{2}$ & $h^{2}$ \\
\hline HT & $5.38 \pm 1.36$ & 0.18 & 0.16 & 1.65 & $0.11(0.02)^{3}$ \\
FAT & $5.30 \pm 1.36$ & 0.14 & 0.62 & 1.38 & $0.10(0.01)^{3}$ \\
CT & $40.30 \pm 16.7$ & 89.1 & 28.2 & 248.1 & $0.36(0.02)^{3}$ \\
Log_nApT & $0.48 \pm 0.22$ & 0.009 & 0.005 & 0.037 & $0.26(0.02)^{3}$ \\
\hline
\end{tabular}

${ }^{1} \mathrm{HT}=$ handling temperament; FAT $=$ farmer-assessed temperament; CT = connection time; Log_nApT = natural logarithm of number of attachments per teat.

${ }^{2} \sigma_{H Y S}^{2}=$ herd $\times$ year $\times$ season variance.

${ }^{3}$ Intraherd heritability: $h^{2}=\frac{\sigma_{A}^{2}}{\sigma_{P}^{2}}$ (Heringstad et al., 2006). Numbers in parentheses are SE.

recorded in conventional milking systems. The genetic correlation between these 2 traits was $0.92( \pm 0.05)$.

\section{Handling Temperament and Farmer- Assessed Temperament}

This study shows that HT is heritable and that the $\mathrm{h}^{2}$ is similar to FAT (0.13), which is used in the genetic evaluation of FAT (SEGES Cattle, 2015-2016). However, it was expected that HT had a higher $h^{2}$, since farmers have less experience recording these traits compared with classifiers (Kramer et al., 2013), which is one reason to replace farmer registrations with classifier registrations. Farmers only record temperament twice a year, whereas classifiers do it as a daily routine when they do the conformation classification in the Nordic countries (Denmark, Sweden, and Finland). On the other hand, farmers handle their cows every day and have coherent observations to assess temperament for the individual cow. However, herd sizes are growing in many countries, and the knowledge of the individual cow might decrease with increasing herd size. Farmers with large herds have less time to assess the individual cow or have many employees that do not necessarily record temperament observations, or both. Kramer et al. (2013) suggested the small herd size in their study compensated for the disadvantages of having farmers scoring behavioral traits; however, the Danish herd size has increased rapidly (Hansen, 2015), and other data sources for a genetic evaluation of temperament might be requested in the future.

A good human-animal relationship is important because a poor relationship has a negative effect on animal productivity and welfare (Rushen et al., 1999; Hemsworth, 2003). Dairy cows react most likely differently to familiar humans (e.g., the farmer and farm employees) compared with unfamiliar humans such as the inseminator, veterinarian, or classifier. In a review by Waiblinger et al. (2006), it is suggested that the animal's response to unknown persons is influenced by previous experiences of treatment/handling of the animal. With that in mind, it becomes questionable if the classifiers record the same trait (HT) as the farmers. This can be addressed by the behavioral response of the cow to familiar and unfamiliar persons. Koba and Tanida (1999) found that miniature pigs appeared to discriminate between familiar and unfamiliar people by the color of their clothes. Despite this, a highly favorable genetic correlation between HT and FAT was found $(0.84 \pm 0.06)$. This indicates that these 2 temperament traits are similar, despite being recorded by either a familiar (the farmer) or unfamiliar person (the classifier).

To our knowledge, no other studies have reported $\mathrm{h}^{2}$ for HT in dairy cows. However, a few studies have been conducted in beef cattle. Le Neindre et al. (1995)

Table 3. Results from multitrait analysis with genetic correlations (above diagonal), heritabilities (on diagonal), and phenotypic correlations (below diagonal), with SE in parentheses

\begin{tabular}{lcccc}
\hline Item $^{1}$ & \multicolumn{1}{c}{ HT } & \multicolumn{1}{c}{ FAT } & CT & Log_nApT \\
\hline HT & $0.15(0.02)^{2}$ & $0.84(0.06)$ & $-0.02(0.11)$ & $-0.10(0.11)$ \\
FAT & $0.18(<0.0001)$ & $0.10(0.007)^{2}$ & $-0.29(0.06)$ & $-0.37(0.07)$ \\
CT & $-0.04(0.31)$ & $-0.06(<0.001)$ & $0.36(0.02)^{2}$ & $0.91(0.01)$ \\
Log_nApT & $-0.01(0.73)$ & $-0.05(<0.01)$ & $0.75(<0.0001)$ & $0.26(0.02)^{2}$ \\
\hline
\end{tabular}

${ }^{1} \mathrm{HT}=$ handling temperament; FAT $=$ farmer-assessed temperament; CT $=$ connection time; Log_nApT $=$ natural logarithm of number of attachments per teat.

${ }^{2}$ Intraherd heritability: $h^{2}=\frac{\sigma_{A}^{2}}{\sigma_{P}^{2}}$ (Heringstad et al., 2006), where $\sigma_{A}^{2}=$ additive variance and $\sigma_{P}^{2}=$ phenotypic
variance. 
and Hoppe et al. (2010) found low moderate $\mathrm{h}^{2}$ for HT (0.11 and 0.36), assessed as flight speed (restrained) and docility (nonrestrained), respectively. Records from these studies are based on cows that are either restrained or nonrestrained, depending on the herd system. Our study includes both restrained and nonrestrained records, which could possibly cause a bias in the data. Still we chose to include all records to maximize the available information. Grignard et al. (2001) estimated the correlation between a docility test (nonrestrained) and a crush test (restrained) using records on 245 Limousine heifers from 10 sires. The correlations between docility and crush test for heifers was $0.29(P<0.001)$ and $0.37(P<0.001)$ when the human was motionless and stroked the animal in crush test. These correlations were higher when measured on daughter groups of sires to $0.88(P<0.001)$ and 0.81 $(P<0.05)$ when the human was motionless and stroked the animal (Grignard et al., 2001). When humans were presented to the animals in handling tests, it improves the correlation between the 2 test types restrained and nonrestrained, suggesting common reactions toward humans (Grignard et al., 2001).

Differences may be present between breeds in level of $\mathrm{h}^{2}$ for HT, and this study reported a lower $\mathrm{h}^{2}$ compared with the studies by Le Neindre et al. (1995) and Hoppe et al. (2010). This indicates that temperament may be influenced by breed, which is also suggested by Murphey et al. (1980). Further studies are required before a general assumption on the level of $h^{2}$ for HT in dairy cattle can be established.

A different method for evaluation of HT was performed by Nkrumah et al. (2007). They used flight speed (meters/second) in beef cattle, which has the advantage of being an objectively recorded trait. The $\mathrm{h}^{2}$ found was relatively high $(0.49 \pm 0.18)$ but subjected with a high SE. This result indicates that the $\mathrm{h}^{2}$ could be increased by using more objectively scored traits.

Our results show that a multitrait model improves slightly the estimation of $\mathrm{h}^{2}$ for HT (Tables 2 and 3). Another advantage of a using multitrait model is that the accuracies of breeding values are improves slightly (Mrode and Thompson, 2014).

\section{Milking Temperament}

This study showed that $\mathrm{h}^{2}$ was larger for CT compared with log_nApT; however, the genetic correlation between FAT and log_nApT was slightly larger than the correlation between FAT and CT. In 3 AMS studies, the $\mathrm{h}^{2}$ for milking temperament was estimated to be in the range from 0.05 to 0.31 using data from DeLaval AMS (Bakke, 2014; Rinell et al., 2014; Carlström et al.,
2016). Rinell et al. (2014) estimated $\mathrm{h}^{2}$ for proportion of attachment failures (0.31) in multiparous Holstein cows. Proportion of attachment failures had the lowest genetic correlation to FAT $(-0.38)$, but it was favorable (Rinell et al., 2014). The genetic correlation between FAT and number of attachment failures was higher $(-0.50)$, but with a lower $h^{2}(0.06)$ for number of attachment failures (Rinell et al., 2014). Bakke (2014) found a favorable genetic relationship between temperament and proportion of milkings with kickoff (0.54) in Nordic Red Cattle. Proportion of incomplete milkings showed a small $h^{2}(0.08)$ with a moderately low genetic correlation to temperament (0.27; Bakke, 2014). Carlström et al. (2016) estimated $a h^{2}$ at $0.05( \pm 0.02)$ for AMS handling time and $0.31( \pm 0.07)$ for proportion of attachment failures. Proportion of attachment failures and AMS handling time had negative and favorable genetic correlations to FAT $(-0.44 \pm 0.15$ and $-0.20 \pm$ 0.15 , respectively).

The 3 AMS studies showed that AMS temperament traits are heritable with favorable correlations to temperament assessed by farmers. These results are similar to results from our study despite the different trait definitions; however, none of the mentioned AMS studies corrected their temperament traits for udder coordinates. This can possibly affect the results because poor udders affect attachment of teat cups, but this effect is not related to temperament, but conformation. In the AMS studies by Bakke (2014) and Rinell et al. (2014) the SE of the $h^{2}$ are not presented, and it is thus difficult to assess if the estimates are significant.

Sewalem et al. (2011) used a bivariate model to estimate $\mathrm{h}^{2}$ for milking temperament recorded by classifiers in first lactation Canadian Holstein cows. Their estimates are within the range of $\mathrm{h}^{2}$ estimates for AMS traits reported by Bakke (2014) and Rinell et al. (2014). The $\mathrm{h}^{2}$ level for milking temperament scored by farmers (0.04-0.07) in the studies by Rensing and Ruten (2005) and Kramer et al. (2013) is lower than the $\mathrm{h}^{2}$ estimated based on records from AMS traits (0.06-0.31; Bakke, 2014; Rinell et al., 2014) and classifiers (0.20; Sewalem et al., 2011).

The genetic correlation structure between HT, milking temperament, and FAT indicates that farmers evaluate 2 different temperament traits when they record their cows for temperament; however, the genetic correlation structure between HT and AMS temperament traits are only based on 816 records (Table 1) and this results in high SE on the genetic correlations. Future studies are required to estimate this correlation structure more accurately. Kramer et al. (2013) used farmers to classify milking and general temperament and estimated $a h^{2}$ of 0.04 and 0.38 , respectively, but 
with a high SE (0.04) for milking temperament. They also presented a moderate genetic correlation between milking and general temperament $(0.34 \pm 0.01)$, which is in accordance with other AMS studies and the present study. These assumptions depend on the fact that AMS traits express milking temperament and HT expresses the cow's HT.

The correlation between FAT scored by farmers with AMS and conventional milking system indicates that recording of FAT is the same in both milking systems. This is important if breeding values for milking temperament will be solely based on data from AMS in the future. Data from AMS have great potential in the future for dairy cattle breeding schemes because large amount of objective records will be available. Carlström et al. (2013) showed that $19 \%$ of Swedish herds have AMS, corresponding to $28 \%$ of the dairy cows in Sweden, and they concluded that there is great potential of using AMS data in the genetic evaluation of milk ability traits. Results from this study show that HT and AMS traits do not reflect the same trait due to low genetic correlations between the 2 temperament traits. Further studies should be conducted to determine the genetic relationship between temperament traits in dairy cattle. However, this study provides evidence that FAT could be divided into handling and milking temperament.

\section{CONCLUSIONS}

From this study, we can conclude that handling and milking temperament are heritable, which is in accordance with previous studies. Moderate estimates of $h^{2}$ were found for milking temperament, which indicates that data from AMS have great potential for use in the breeding value evaluation. The $\mathrm{h}^{2}$ for HT is small but slightly larger than the FAT trait in the current Nordic breeding value evaluation. The genetic relationship between FAT and the new HT shows a highly favorable correlation. The genetic relationships between milking temperament traits and FAT are moderate, but favorable. The genetic relationships between milking temperament traits and HT are low and with high SE. The results from this study show a basis for further investigation of using these new temperament traits in the genetic evaluation of temperament.

\section{ACKNOWLEDGMENTS}

The authors thank the Danish Holstein association for financing data registration of handling temperament and making it possible to investigate this topic. The authors also thank the Danish classifiers Carsten
L. Dahl, Jørgen Knudsen, Søren K. Christensen, Jakob Edstrand, Torben Andersen, Mogens H. Madsen, and Villy Nicolajsen for a great job with registration of handling temperament in Danish herds. This study was carried out in close cooperation with the Nordic Cattle Genetic Evaluation, and the authors gratefully acknowledge the Nordic Cattle Genetic Evaluation for providing help with data editing and genetic analysis.

\section{REFERENCES}

Bakke, K. A. 2014. Sammenhenger mellom lynne og utmelkingsegenskaper hos NRF, vurdert subjektivt og registrert objektivt i melkerobot. MS Thesis. Department of Animal and Aquacultural Sciences, Norwegian University of Life Sciences, Ås.

Burrow, H. M. 1997. Measurements of temperament and their relationships with performance traits. Pages 477-495 in Proc. Anim. Breed. Abstr.

Carlström, C., G. Pettersson, K. Johansson, E. Strandberg, H. Stålhammar, and J. Philipsson. 2013. Feasibility of using automatic milking system data from commercial herds for genetic analysis of milkability. J. Dairy Sci. 96:5324-5332.

Carlström, C., E. Strandberg, G. Pettersson, K. Johansson, H. Stålhammar, and J. Philipsson. 2016. Genetic associations of teat cup attachment failures, incomplete milkings, and handling time in automatic milking systems with milkability, temperament, and udder conformation. Acta Agric. Scand. A Anim. Sci. 66:75-83.

Grignard, L., X. Boivin, A. Boissy, and P. Le Neindre. 2001. Do beef cattle react consistently to different handling situations? Appl. Anim. Behav. Sci. 71:263-276.

Hansen, O. K. 2015. Developments in milk yield as measured in milk recording. Vol. 2018. Accessed Jun. 1, 2018. https://www.landbrugsinfo.dk/Kvaeg/RYK/Sider/ Developmentsinmilkyieldasmeasuredinmilkrecording.aspx.

Hemsworth, P. H. 2003. Human-animal interactions in livestock production. Appl. Anim. Behav. Sci. 81:185-198.

Heringstad, B., D. Gianola, Y. Chang, J. Ødegård, and G. Klemetsdal. 2006. Genetic associations between clinical mastitis and somatic cell score in early first-lactation cows. J. Dairy Sci. 89:2236-2244.

Hoppe, S., H. Brandt, S. König, G. Erhardt, and M. Gauly. 2010. Temperament traits of beef calves measured under field conditions and their relationships to performance. J. Anim. Sci. 88:1982-1989.

Ivemeyer, S., U. Knierim, and S. Waiblinger. 2011. Effect of humananimal relationship and management on udder health in Swiss dairy herds. J. Dairy Sci. 94:5890-5902.

Jensen, J., and P. Madsen. 2002. Calculation of standard errors of estimates of genetic and phenotypic parameters in DMU. Research Centre Foulum, Danish Institute of Agricultural Sciences, Tjele, Denmark.

Koba, Y., and H. Tanida. 1999. How do miniature pigs discriminate between people? The effect of exchanging cues between a nonhandler and their familiar handler on discrimination. Appl. Anim. Behav. Sci. 61:239-252.

Kramer, M., M. Erbe, B. Bapst, A. Bieber, and H. Simianer. 2013. Estimation of genetic parameters for novel functional traits in Brown Swiss cattle. J. Dairy Sci. 96:5954-5964.

Lauritsen, U. 2014. AMS sampling in Denmark. Accessed Jun. 1, 2018. https://www.landbrugsinfo.dk/Kvaeg/RYK/Sider/ AMSsamplinginDenmark.aspx.

Le Neindre, P., G. Trillat, J. Sapa, F. Ménissier, J. Bonnet, and J. Chupin. 1995. Individual differences in docility in Limousin cattle. J. Anim. Sci. 73:2249-2253.

Madsen, P., and J. Jensen. 2013. DMU A Package for Analysing Multivariate Mixed Models. Version 6, release 5.2. Center for Quantitative Genetics and Genomics, Dept. of Molecular Biology and Genetics, University of Aarhus Research Centre Foulum. Vol. 2017. 
Mrode, R. A., and R. Thompson. 2014. Linear Models for the Prediction of Animal Breeding Values. CABI, Wallingford, UK.

Murphey, R. M., F. A. M. Duarte, and M. C. T. Penedo. 1980. Approachability of bovine cattle in pastures: breed comparisons and a breed $\times$ treatment analysis. Behav. Genet. 10:171-181.

Nkrumah, J., D. Crews, J. Basarab, M. Price, E. Okine, Z. Wang, C. Li, and S. Moore. 2007. Genetic and phenotypic relationships of feeding behavior and temperament with performance, feed efficiency, ultrasound, and carcass merit of beef cattle. J. Anim. Sci. 85:2382-2390.

Pedersen, J., M. K. Sørensen, M. Toivonen, J. Eriksson, and G. P. Aamand. 2008. Report on economic basis for a Nordic total merit index. Report from Nordic Cattle Genetic Evaluation, Skejby, Denmark.

Rensing, S., and W. Ruten. 2005. Genetic evaluation for milking speed in German Holstein population using different traits in a multiple trait repeatability model. Interbull Bull. 163-166.

Rinell, E., C. Carlström, B. Heringstad, and E. Strandberg. 2014. Genetic associations between behavior traits recorded by automatic milking systems and temperament of Swedish Holsteins. Pages 1-3 in Proceedings 10th World Congress of Genetics Applied to Livestock Production, Vancouver, Canada. Department of Animal and Aquacultural Sciences, Norwegian University of Life Sciences, Ås, Norway.

Rushen, J., A. A. Taylor, and A. M. de Passillé. 1999. Domestic animals' fear of humans and its effect on their welfare. Appl. Anim. Behav. Sci. 65:285-303.

SEGES Cattle. 2015-2016. Year statistics for breeding. Vol. 2017. Nordic Cattle Genetic Evaluation. Agro Food Park 15. Aarhus, Denmark.

Sewalem, A., F. Miglior, and G. Kistemaker. 2011. Genetic parameters of milking temperament and milking speed in Canadian Holsteins. J. Dairy Sci. 94:512-516.

Waiblinger, S., X. Boivin, V. Pedersen, M.-V. Tosi, A. M. Janczak, E. K. Visser, and R. B. Jones. 2006. Assessing the human-animal relationship in farmed species: A critical review. Appl. Anim. Behav. Sci. 101:185-242. 